\title{
ATM Kinase Inhibitor AZD1390
}

National Cancer Institute

\section{Source}

National Cancer Institute. ATM Kinase Inhibitor AZD1390. NCI Thesaurus. Code C150167.

An orally bioavailable inhibitor of ataxia telangiectasia mutated (ATM) kinase, with potential antineoplastic activity. Upon oral administration, AZD1390 targets and binds to AT M, thereby inhibiting the kinase activity of ATM and ATM-mediated signaling. This prevents DNA damage checkpoint activation, disrupts DNA damage repair, induces tumor cell apoptosis, and leads to cell death in ATM-overexpressing tumor cells. AZD1390 hypersensitizes tumors to chemo/radiotherapy. In addition, AZD1390 is able to cross the blood-brain barrier (BBB). ATM, a serine/threonine protein kinase belong ing to the phosphatidylinositol 3-kinase-related kinase (PIKK) family of protein kinases, is upregulated in a variety of cancer cell types. It is activated in response to DNA doublestrand breaks (DSB) and plays a key role in DNA repair. 